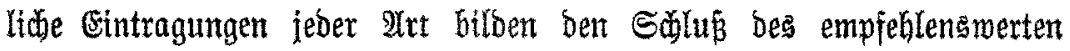
unb gut ausgeftatteten Ralenbers.

4. Beibmannsheil. Forit unb Jagbfalenber für bas Salin 1913.

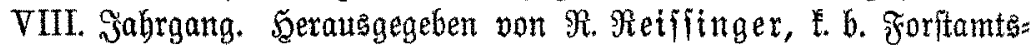

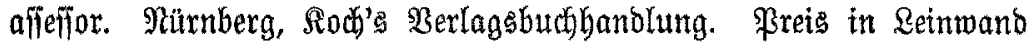
geb. $1,50$.

Der folib ausgeftattete Salenber bietet neben bem in affer Ralenbern enthaltenen Beit= und Motizfalenber, überfidten uno Tabellen nod) einen vorzugsmeife für bayerifje Berbältniffe berechneten foritlitien uno jago= liden IInbang mit reidem Sngalt, wie bishber. Dem vorliegenoen Sabr= gang ftno einige neue 2biantilte eingefügt: fo über bas foritlide Radibar=

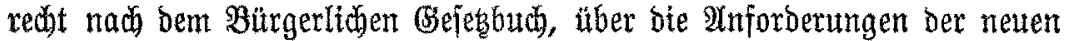
bayer. Sidonoronung an bì Beräte zur Golzaufnahme, bie Martierung von Bögeln. Der Şinweis auf widtige Gejebe uno Beroromungen ift bis auf bie Gegenwart ergänzt, ein jolder alf bie widttgeren forftlidjen uno jagditchen झrtifel fritherer Sahrgänge angefügt. Der Falender ver= bient befte Empfehlung.

\title{
IV. Jutizen.
}

Profeffor Dr. ZXolf freih. von Guttenberg.

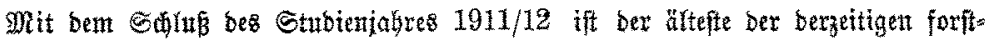
Itten Frofefforen, Sofrat Dr. Moolf b. (3) utenberg, Brofeffor ber Betriebslebre an

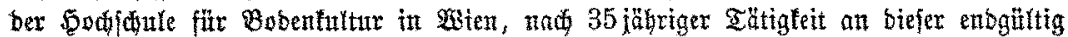

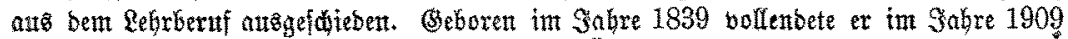

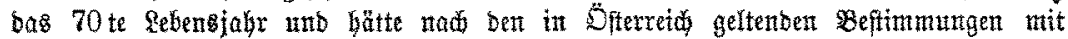
Sđlü bes Stubientiobres 1909/10 fein 2rmt nieberlegen mulfien - bod murbe bem

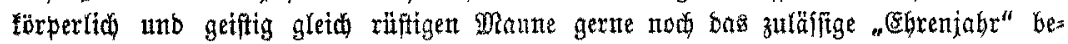

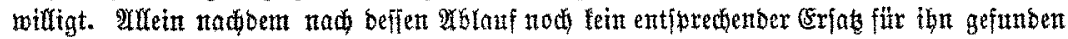
wax, griff ex aud im Stubientabr 1911/12 nod aushelfenb ein, um nit beffen Sd̆ht wun ber geltebten Sehretätiglett fitr immer žl entjagen.

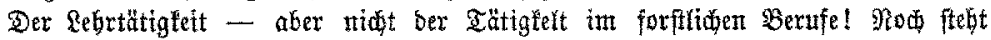

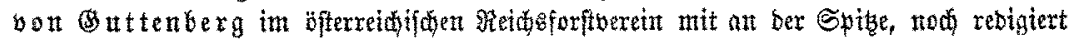

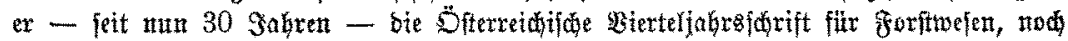

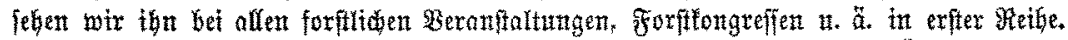

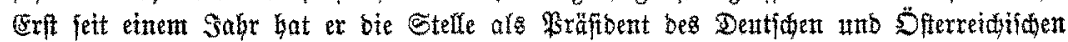

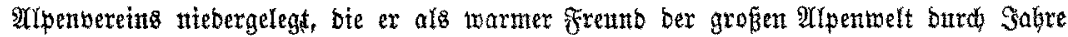

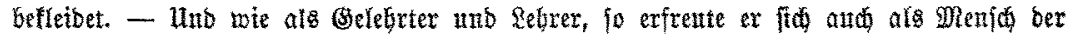

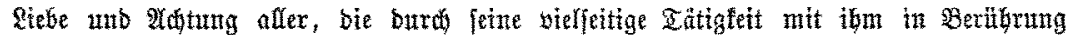
fomment, insbejonbere aber ant ber afobemifden Sngents, ber ex ftets warme Snmpatbie

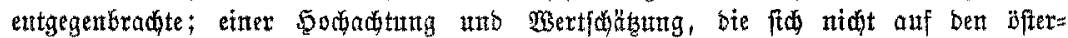
reidifigett Raiferftad beiduränft!

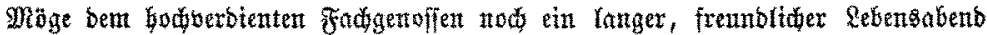
beficiteben fein!

Dr. Zürf. 